\title{
Heritability, Correlation and Path Analysis among Yield and Yield Attributing Traits for Drought Tolerance in an Interspecific Cross Derived from Oryza sativa $x$ O. glaberrima Introgression Line under Contrasting Moisture Regimes
}

\author{
Surapaneni SAIKUMAR ${ }^{1,2,3, *}$, Akula SAIHARINI ${ }^{1}$, Dass AYYAPPA ${ }^{3}$, \\ Guntupalli PADMAVATHI ${ }^{3}$, V. Vinay SHENOY ${ }^{1}$ \\ ${ }^{1}$ Barwale Foundation, Barwale Chambers, \#3-6-666, Street No.10, Himayathnagar, Hyderabad 500 029, India; \\ saikumar@barwalefoundation.org (*orrespondingauthor) \\ ${ }^{2}$ Department of Genetics, Osmania University, Hyderabad, India \\ ${ }^{3}$ Directorate of Rice Research, Rajendra nagar, Hyderabad 500 030,India; ayyyappadass81@gmail.com
}

\begin{abstract}
Drought is a major constraint for rainfed lowland and upland rice productivity throughout world. A backcross inbred population derived from 'Swarna' and 'WAB450-I-B-P-157-2-1' (Oryza sativa L. x O. glaberrima) was evaluated under both irrigated and lowland drought stresses for yield and yield related traits across three different seasons. Significant differences were found among all the analyzed traits. Coefficients of variation were recorded relatively high for filled grains per panicle, spikelet fertility, test weight, harvest index and grain yield and low for panicle length under both conditions during the study interval. Broad sense heritability varied from 0.28 (panicle number) to 0.83 (plant height) under stress and 0.31 (test weight) to 0.86 (plant height) under control. However, heritability estimates for grain yield and harvest index were found to be similar under both conditions. Traits such as filled grains per panicle, spikelet fertility, harvest index and grain yield recorded higher values of both heritability, as well as genetic advance under both conditions, indicating the suitability of these traits as selection criteria to derive high yielding genotypes for drought prone regions. Harvest index exhibited maximum positive direct effect on grain yield under both the conditions; in addition, filled grains per panicle, spikelet fertility and biomass had positive direct effect on grain yield under both irrigated and lowland drought stresses state. Hence, for improving the rice yield under lowland drought ecology, a genotype should posses a large number of panicles per plant, filled grains per panicle, high spikelet fertility and maintains higher biomass and harvest index.
\end{abstract}

Keywords: grain yield, genetic advance, heritability, path analysis, rice

\section{Introduction}

Rice is one of the most important food crops for Africa and Asia, as it plays an irreplaceable role in Indian national food security. It is cultivated in a wide range of ecosystems under varying temperature and water regimes. Majority of rice is contributed from irrigated ecosystem, where yield increase is now getting stagnated (Peng et al., 1999). However, rainfed ecosystem contributes only with a quarter to the total rice production, even though it occupies $50 \%$ of the total rice area in the world (Maclean et al., 2002). Drought is the major environmental constraints to rice productivity in rainfed areas (Farooq et al., 2009; Serraj et al., 2009). At all stages of rice growth and development, drought is the major stress, but it has the greatest impact during flowering, when grain formation is suppressed. This results in considerable yield losses under rainfed and upland ecosystems (Serraj et al., 2009). Sensitivity of rice to drought stress is more pronounced during the reproductive stage; even moderate stress can result in drastic reduction in grain yield (O'Toole et al., 1982; Pantuwan et al., 2002; Lanceras et al., 2004; Venuprasad et al., 2009).

Young seedlings can recover much better upon relief from drought, although reduction in yield may be better anticipated if leaf area damage and tiller numbers reduction are known (Cruz et al., 1986). The severity of vegetativestage drought stress will depend on the plant's ability to avoid stress either through a deeper or more extensive root 
system, or the ability to recover upon rewatering (Yoshida and Hasegawa, 1982) and increase the dry matter accumulation in sinks. The amount of accumulated dry matter in green leaves is different from one cultivar to another cultivar (Abarshahr et al., 2011). Yambao and Ingram (1988) observed that withholding water for 15 days during the panicle initiation stage reduced yield by $70 \%$, during flowering $88 \%$ and during grain filling $52 \%$. Drought at anthesis can delay or prevent flowering, or result in pollen or spikelet sterility (Saini and Westgate, 2000). Drought significantly delays peduncle elongation, trapping a very large proportion of the panicle within the flag leaf sheath because the expression of cell-wall invertase genes is decreased (Ji et al., 2005). Spikelet sterility is mainly due to the inhibition of starch accumulation in pollen grains or failure of anther dehiscence (Zhu et al., 2004). Drought that occurs during these processes causes damage to reproductive organs. High yield under drought stress was associated with continued leaf area development, root growth, continued photosynthesis, maintenance of high biomass production, spikelet fertility and harvest index during reproductive phase (Bouman et al., 2005; Atlin et al., 2006).

To meet the ever-growing demand for rice by 2030, a significant increase, of at least $35 \%$ in yield is needed (Bouman et al., 2007). Development of drought tolerant cultivars still remains a major objective for increasing productivity under rainfed ecosystem. Understanding the inheritance of the interest traits is the key for success in any breeding programme. However, progress in breeding for drought resistance has been slow (Fukai and Cooper, 1995). Breeding for drought tolerance in rice with high yield potential is quite challenging due to its complex genetic nature (polygenic nature), poor understanding of physiological as well as molecular mechanisms underlying the trait and intensity, timing and duration of drought stress in lowland and upland conditions across seasons

Another major concern in drought breeding programs is that by genetic variability, as manifested by various alleles that a breeder could choose from, inter-varietal breeding program is fast eroding. This has negatively impacted gainper-cycle in crop improvement endeavor. It is imperative that the breeders seek new sources of genetic variability to keep up the pace of crop improvement lest the threat of yield plateau persists. Population with high variability serves as a prime source in developing high yielding genotypes coupled with drought tolerance for effective selection. Genetic improvement mainly depends on the amount of genetic variability present in the population which is a ubiquitous property of all species in nature. These genetic variations might be either heritable or non-heritable due to differences either in the genetic constitution of the individuals or influenced by the environment in which they are grown. The magnitude of variation due to heritable component is very important, because it would be a guide for selection of genitors for crop improvement. Importance of variability for drought tolerance, yield and yield related traits have been emphasized by many workers in past (Selvarani and Rangaswamy, 1997; Venkataramana and Hittalmani, 1999; Kumar et al., 2007). Correlation analysis provides a good measure of the association between characters and helps to identify the most important character(s) to be considered for effective selection for increasing yield. The extent of direct and indirect effects of component characters on yield, elucidated through path coefficient analysis using correlations, helps further to choose the right characters as selection criteria (Chakraborthy et al., 2010).

\section{Materials and methods}

\section{Location}

The study was carried at experimental farm of the Barwale Foundation, Maharajpet, Hyderabad, India, located at latitude of $17^{\circ} 24^{\prime} \mathrm{N}$ and longitude of $78^{\circ} 12^{\prime} \mathrm{E}$ and an altitude of $536 \mathrm{~m}$ above mean sea level, during 2012 (dry season and wet season) and 2013 (dry season) under stress, as well as irrigated, ecosystems.

\section{Plant material}

Swarna, a semi-dwarf high yielding Indica line, occupies around $12 \%$ of the total rice production area in India. However, Swarna is highly susceptible to moisture stress (Venuprasad et al., 2009). WAB450-I-B-P-157-2-1 is an upland ecotype derived from $O$. glaberrima and $O$. sativa by African rice center (WARDA), known for its drought tolerance, deep root, early vigor, weed competitiveness, pest or disease resistance, also known as a valuable genetic material for drought-prone environments (Saikumar et al., 2014). Swarna (female) was crossed with WAB450-I-B-P157-2-1 to produce a set of $202 \mathrm{BC}_{1} \mathrm{~F}_{6}$ back cross inbred lines (BILs) by single seed descent method. The obtained BILs along with their genitors and checks were evaluated for drought response at lowland reproductive stage stress for estimation of genetic variability parameters.

\section{Field experiments}

Six field experiments were conducted during 2012 and 2013 (dry season - DS and wet seasons - WS) with varied level of moisture stress. They comprised of three lowland irrigated trials (one each during DS 2012, DS 2013 and WS 2012), and three lowland stress trials (one each during DS 2012, WS 2012 and DS 2013). All the experiments were laid out as randomized complete block design with two replications. A plot size of $1.2 \mathrm{~m}^{2}$ was used for lowland trials. 25-day old seedlings were transplanted into the main field. One seedling was transplanted per hill at a spacing of $20 \mathrm{~cm}$ between hills as well as rows. After transplanting, approximately $5 \mathrm{~cm}$ of standing water was maintained in the field until draining, before harvest for control trails. Inorganic NPK fertilizer was applied at the rate of 100-50$50 \mathrm{~kg} \mathrm{ha}^{-1}$. Weeds and insect pests were controlled chemically in order to ensure a healthy crop. Whereas for stress trials irrigation was withheld approximately 30 DAT until maturity for wet season trails. In dry season stress trials, DS 2012 and DS 2013, irrigation was withheld until the water level beneath the soil reaches to $-100 \mathrm{~cm}$ with the help of piezo-meter or moisture tension reached $-60 \mathrm{k} \mathrm{Pa}$ at 30 $\mathrm{cm}$ depth. Fields were then re-irrigated by flash flooding, and drained again after approximately $24 \mathrm{~h}$ to save the plants from being exposed to very severe stress that leads to a loss of all genetic variability for grain yield (GY) under reproductive stage stress (RS) in the mapping population (Kumar et al., 2007). This cycle was repeated until harvest. Severe leaf rolling and leaf drying was observed during each 
340

stress period. Crop received a rain fall of rainfall $(335.0 \mathrm{~mm}$ (WS 2012), $37.3 \mathrm{~mm}$ (DS 2012) and $0.0 \mathrm{~mm}$ (DS2013)) and evapo-transpiration (ET) was $842.0 \mathrm{~mm}$ (WS 2012), $957.2 \mathrm{~mm}$ (DS2012) and $987.5 \mathrm{~mm}$ (DS2013).

\section{Data collection}

In all the trials data was recorded on days to 50 percent flowering (DFF) as number of days from sowing to panicle emergence in 50 percent of the plants. At physiological maturity, plant height $(\mathrm{PH})$, panicle number $(\mathrm{PN})$, panicle length (PL), filled grains/panicle (FGP), spikelets number /panicle (SNP), spikelet fertility (SF), test weight (TW), grain yield $(\mathrm{GY})$, biomass $(\mathrm{BM})$ and harvest index $(\mathrm{HI})$ were recorded. Physiological traits such as leaf chlorophyll content (SPAD) and canopy temperature (CT) were recorded at reproductive stage during dry season 2013 only. All the above mentioned traits were measured from three randomly selected plants per BIL per replication.

Mean data was generated for all the BILs under both control and stress conditions. For each genotype per replication analysis of variance and covariance were used as per methodology advocated by Panse and Sukhatme (1985). Correlation coefficients for all traits were estimated according to Johnson et al. (1955) for all three seasons. Broad-sense heritability was calculated for all traits in both stress and control conditions, for each season using formula:

$$
h_{b}^{2}=\sigma^{2} g / \sigma^{2} p \text { or } \sigma^{2} p=\sigma^{2} g+\left(\sigma^{2} e / r\right)
$$

Where $\sigma^{2} \mathrm{p}$ is the phenotypic variance, $\sigma^{2} \mathrm{~g}$ is the genotypic variance, $\sigma^{2}$ e is the error variance and $r$ is the number of replications in the season.

Genotypic and phenotypic correlations were partitioned into direct and indirect effects through path analysis, using the technique outlined by Dewey and Lu (1959). All statistical analyses were carried out using the softwares GENERES and CROPSTAT version 7.2.3.

\section{Results and discussion}

Results from the analysis of variance revealed that significant genetic variation exists in BIL population for all traits studied, under both stress and control conditions during DS 2012, WS 2012 and DS 2013 ( < 0.01), which is mainly attributed to the large genetic variability present in the two parental lines used in breeding program. Such a wide variation indicated the scope for improving the population for these characters with respect to drought and other related quantitative traits. The BILs were compared with their parent's value distribution, considering the grain yield and other quantitative traits (Tab. 1).

Tab. 1. Range, mean and LSD 5\% of the Swarna/WAB450-I-B-P-157-2-1 population and parents under reproductive stage stress (S) and control (C) conditions in DS 2013, WS 2012 and DS 2012

\begin{tabular}{|c|c|c|c|c|c|c|c|c|c|c|c|c|c|c|c|c|}
\hline \multirow[b]{2}{*}{ Trait } & & \multicolumn{5}{|c|}{ DS 2013} & \multicolumn{5}{|c|}{ WS 2012} & \multicolumn{5}{|c|}{ DS 2012} \\
\hline & & Range & Mean & $\begin{array}{c}\text { LSD } \\
5 \%\end{array}$ & Swarna & WAB & Range & Mean & $\begin{array}{c}\text { LSD } \\
5 \%\end{array}$ & Swarna & WAB & Range & Mean & $\begin{array}{c}\text { LSD } \\
5 \%\end{array}$ & Swarna & WAB \\
\hline \multirow{2}{*}{ DFF } & $S$ & $98.0-151.0$ & 133.8 & 7.4 & 153.0 & 92.5 & $89.0-133.0$ & 108.2 & 3.9 & 122.0 & 87.0 & $99.5-145.0$ & 137.1 & 2.3 & 155.0 & 91.0 \\
\hline & $\mathrm{C}$ & $90.0-126.0$ & 113.2 & 3.1 & 125.0 & 84.0 & $87.5-120.0$ & 105.1 & 7.5 & 117.0 & 83.0 & $89.0-120.0$ & 109.5 & 3.4 & 115.8 & 87.5 \\
\hline \multirow{2}{*}{ PH } & S & $45.0-90.0$ & 54.1 & 5.5 & 56.0 & 89.5 & $55.7-108.5$ & 71.6 & 7.9 & 70.2 & 98.0 & $32.5-98.5$ & 54.5 & 5.1 & 51.0 & 85.7 \\
\hline & C & 63.3-106.1 & 78.3 & 4.0 & 82.7 & 115.3 & $78.3-123.0$ & 94.1 & 9.2 & 90.3 & 125.7 & $72.5-119.0$ & 92.7 & 7.5 & 89.5 & 116.0 \\
\hline \multirow{2}{*}{$\mathrm{PN}$} & $S$ & $6.0-38.5$ & 24.9 & 10.9 & 23.3 & 5.0 & $4.2-28.5$ & 17.7 & 5.8 & 17.0 & 6.0 & $6.7-44.0$ & 25.6 & 3.8 & 19.0 & 6.0 \\
\hline & $\mathrm{C}$ & $6.8-43.4$ & 20.1 & 4.5 & 25.0 & 7.0 & $3.9-23.3$ & 15.2 & 0.2 & 17.0 & 7.0 & $4.0-24.8$ & 16.5 & 5.8 & 21.0 & 8.0 \\
\hline \multirow{2}{*}{ PL } & $S$ & $13.2-22.7$ & 16.9 & 2.9 & 18.0 & 23.5 & $15.6-26.1$ & 20.3 & 4.4 & 18.0 & 25.0 & $12.7-21.3$ & 17.6 & 0.8 & 16.0 & 24.0 \\
\hline & $\mathrm{C}$ & $16.5-26.7$ & 20.8 & 0.7 & 20.3 & 28.0 & $19.0-28.8$ & 22.7 & 0.1 & 22.0 & 29.0 & $19.8-27.3$ & 23.0 & 2.2 & 18.7 & 28.1 \\
\hline \multirow{2}{*}{ FGP } & $S$ & $0.0-161.0$ & 45.2 & 67.1 & 0.0 & 76.5 & $26.0-176.0$ & 145.7 & 90.8 & 33.0 & 108.5 & $22.0-131.7$ & 59.8 & 8.5 & 0.0 & 66.0 \\
\hline & $\mathrm{C}$ & $78.2-248.9$ & 174.4 & 51.1 & 91.0 & 132.0 & $107.2-319.2$ & 253.5 & 66.1 & 109.0 & 193.0 & $83.8-252.5$ & 149.4 & 47.7 & 95.2 & 128.0 \\
\hline \multirow{2}{*}{ SF } & $S$ & $0.0-78.0$ & 26.5 & 17.4 & 0.0 & 70.0 & $23.7-87.0$ & 62.4 & 29.4 & 34.2 & 80.6 & $15.1-82.5$ & 52.3 & 6.6 & 0.0 & 69.1 \\
\hline & $\mathrm{C}$ & $38.5-93.9$ & 72.4 & 0.5 & 75.0 & 85.6 & $55.5-97.7$ & 81.9 & 6.2 & 80.6 & 94.0 & $43.9-98.0$ & 76.9 & 17.0 & 77.0 & 88.2 \\
\hline \multirow{2}{*}{ TW } & $S$ & $0.0-18.6$ & 7.2 & 2.8 & 0.0 & 24.2 & $6.0-31.5$ & 14.5 & 6.0 & 8.0 & 27.0 & $5.5-26.0$ & 12.1 & 0.7 & 0.0 & 25.0 \\
\hline & $\mathrm{C}$ & $15.5-35.1$ & 20.8 & 4.7 & 16.0 & 32.6 & $13.8-33.5$ & 21.7 & 0.9 & 16.0 & 32.0 & $15.8-32.0$ & 20.6 & 12.3 & 16.2 & 31.8 \\
\hline \multirow{2}{*}{ BM } & S & $4.8-13.7$ & 7.8 & 3.5 & 9.8 & 7.7 & $4.6-15.3$ & 8.5 & 3.3 & 10.8 & 6.8 & $4.6-15.6$ & 8.7 & 0.4 & 7.4 & 6.1 \\
\hline & C & $8.06-18.6$ & 11.9 & 2.1 & 12.8 & 10.3 & $7.2-16.9$ & 11.6 & 2.9 & 15.7 & 7.9 & $5.9-15.3$ & 12.1 & 2.0 & 10.7 & 7.7 \\
\hline \multirow{2}{*}{$\mathrm{HI}$} & $S$ & $0.0-0.3$ & 0.06 & 0.04 & 0.0 & 0.16 & $0.0-0.5$ & 0.2 & 0.1 & 0.05 & 0.23 & $0.0-0.3$ & 0.1 & 0.0 & 0.0 & 0.2 \\
\hline & C & $0.25-0.6$ & 0.45 & 0.1 & 0.5 & 0.39 & $0.3-0.6$ & 0.5 & 0.1 & 0.5 & 0.5 & $0.2-0.6$ & 0.6 & 0.1 & 0.5 & 0.5 \\
\hline \multirow[t]{2}{*}{ GY } & S & $0.0-2.1$ & 0.43 & 0.2 & 0.0 & 1.2 & $0.0-4.0$ & 2.2 & 1.0 & 0.5 & 1.5 & $0.0-2.6$ & 0.7 & 0.5 & 0.0 & 1.5 \\
\hline & $\mathrm{C}$ & $2.8-8.5$ & 5.43 & 1.5 & 5.2 & 3.9 & $2.5-11.1$ & 6.4 & 2.1 & 5.3 & 3.9 & $2.2-9.4$ & 6.8 & 1.0 & 5.1 & 3.3 \\
\hline \multirow{2}{*}{ SPAD } & S & $38.5-45.2$ & 42.8 & 2.1 & 45.7 & 44.0 & - & - & - & - & - & - & - & - & - & - \\
\hline & C & $29.2-44.4$ & 39.4 & 3.8 & 48.7 & 45.1 & - & - & - & - & - & - & - & - & - & - \\
\hline \multirow{2}{*}{ CT } & S & $35.2-42.2$ & 37.3 & 3.8 & 39.5 & 36.2 & - & - & - & - & - & - & - & - & - & - \\
\hline & C & $22.1-34.6$ & 28.8 & 0.3 & 31.5 & 29.6 & - & - & - & - & - & - & - & - & - & - \\
\hline
\end{tabular}

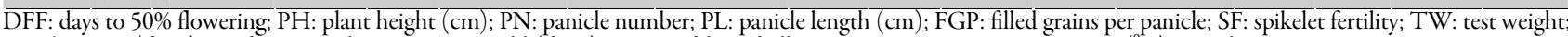
BM: biomass (tha 1 ); HI: harvest index; GY: grain yield (tha 1 ); SPAD: chlorophyll content; CT: canopy temperature $\left({ }^{\circ} \mathrm{C}\right)$; DS: dry season; WS: wet season; S: stress: C: control 
Transgressive segregants with superior performance over the best yielding (under drought) of their genitors were observed during population screening under both the conditions. Such transgressive lines suggest either those favorable additive alleles are brought by both parents, and/or that complementary interactions occur between alleles of different origins. Range, mean, LSD5\% of population in comparison with parents for all three seasons are presented in Tab. 1.

Variance and coefficient of variation

The magnitude of genetic variation and environmental effects involved in the expression of different characters were determined by phenotypic and genotypic coefficients of variation (Tab. 2). Magnitude of PCV was found to be higher than GCV for all the traits under both control and stress, and PCV was higher for stress experiments in comparison with control ones for all the traits across all seasons. Further traits such as GY, HI, FGP, SF and TW displayed very high coefficients of variation (GCV and PCV) among yield and yield attributing traits, high to moderate for DFF, PH, PN and BM and low for PL, SPAD (DS 2013) and CT (DS 2013) under both the conditions across all three seasons, indicating the influence of environment (water stress) in the expression of these traits, with GY and $\mathrm{HI}$ being affected to a greater extent by stress environment. Further, there existed a large difference between the values recorded for GCV and PCV in the present study; such a large difference between GCV and PCV reflects a high environmental influence on the expression of traits. These findings for coefficient of variation (GCV and PCV) were similar to that of Akinwale et al. (2011) and Sadeghi et al. (2011). The GCV ranged from 9.8 (PL) to 136.1 (GY) in DS 2013, 7.1 (PL) to 52.7 (HI) in WS 2012 and 8.7 (PL) to 81.4 (HI) in DS 2012 under stress and 7.2 (PL) to 21.9 (FGP) in DS 2013, 7.3 (PL) to 23.8 (FGP) in WS 2012 and 5.5 (PL) to 16.5 (FGP) in DS 2012 under control conditions. Similarly, the values of PCV ranged from 13.1 (PL) to 195.6 (HI) in DS 2013, 11.7 (DFF) to 65.9 (GY) in WS 2012 and 12.2 (DFF) to $132.3(\mathrm{HI})$ in DS 2012 under stress and $8.4(\mathrm{PL})$ to 25.8 (FGP) in DS 2013, 8.2 (PL) to 27.3 (FGP) in WS 2012 and 7.3 (PL) to 23.2 (FGP) in DS 2012 under control environment. Further, physiological traits SPAD and CT during DS 2013 recorded lower values of both GCV and PCV (except in control), when compared to yield component traits. Transgressive segregation in both directions was observed for most traits under drought stress and control, indicating that both parents transmitted favourable alleles for each trait.

Tab. 2. GV, PV, GCV, PCV, broad-sense heritability $\left(b^{2}{ }_{b}\right)$, genetic advance (GA) yield and yield components of the Swarna/WAB450-I-B-P-157-21 population under reproductive stage stress (S) and control (C) conditions in DS 2013, WS 2012 and DS 2012

\begin{tabular}{|c|c|c|c|c|c|c|c|c|c|c|c|c|c|c|c|c|c|c|c|}
\hline \multirow[b]{2}{*}{ Trait } & \multicolumn{7}{|c|}{ DS2013 } & \multicolumn{6}{|c|}{ WS2012 } & \multicolumn{6}{|c|}{ DS2012 } \\
\hline & & GV & PV & GCV & PCV & $H$ & GA & GV & PV & GCV & PCV & $H$ & GA & GV & PV & GCV & PCV & $H$ & GA \\
\hline \multirow{2}{*}{ DFF } & $S$ & 464.0 & 586.4 & 16.1 & 20.0 & 0.79 & 32.6 & 89.5 & 123.1 & 8.7 & 11.7 & 0.73 & 17.7 & 171.7 & 220.1 & 9.5 & 12.2 & 0.78 & 19.6 \\
\hline & C & 108.3 & 131.8 & 9.1 & 10.9 & 0.82 & 18.7 & 68.0 & 82.4 & 7.8 & 8.6 & 0.82 & 14.7 & 55.9 & 66.5 & 7.4 & 8.3 & 0.84 & 14.7 \\
\hline \multirow{2}{*}{$\mathrm{PH}$} & $S$ & 38.0 & 45.7 & 11.4 & 13.5 & 0.83 & 21.4 & 35.3 & 51.4 & 8.2 & 15.0 & 0.69 & 14.1 & 42.6 & 53.8 & 11.9 & 14.0 & 0.79 & 22.9 \\
\hline & C & 37.9 & 43.9 & 7.8 & 8.6 & 0.86 & 15.3 & 27.4 & 33.8 & 8.1 & 9.6 & 0.81 & 8.5 & 31.5 & 37.5 & 5.9 & 8.4 & 0.84 & 10.3 \\
\hline \multirow{2}{*}{$\mathrm{PN}$} & $S$ & 12.2 & 43.0 & 14.0 & 26.3 & 0.28 & 15.3 & 4.2 & 12.9 & 11.5 & 20.2 & 0.32 & 13.6 & 49.9 & 91.2 & 27.6 & 48.6 & 0.55 & 54.8 \\
\hline & C & 9.1 & 14.4 & 15.0 & 18.8 & 0.63 & 24.6 & 6.8 & 8.8 & 17.1 & 22.3 & 0.77 & 35.2 & 3.5 & 6.1 & 11.2 & 10.5 & 0.57 & 12.3 \\
\hline \multirow{2}{*}{ PL } & $S$ & 2.8 & 4.9 & 9.8 & 13.1 & 0.56 & 15.1 & 2.1 & 7.1 & 7.1 & 13.1 & 0.30 & 8.0 & 2.4 & 4.5 & 8.7 & 13.8 & 0.52 & 173 \\
\hline & C & 2.3 & 2.8 & 7.2 & 8.4 & 0.83 & 14.5 & 2.8 & 3.1 & 73 & 8.2 & 0.89 & 15.1 & 1.6 & 2.8 & 5.5 & 73 & 0.57 & 8.6 \\
\hline \multirow{2}{*}{ FGP } & $S$ & 2311.0 & 3471.1 & 106.2 & 130.2 & 0.67 & 78.5 & 1392.5 & 2712.9 & 25.9 & 41.2 & 0.51 & 33.6 & 452.8 & 904.2 & 35.6 & 89.9 & 0.50 & 71.8 \\
\hline & C & 1372.1 & 1652.2 & 21.9 & 25.8 & 0.83 & 44.1 & 3662.4 & 4786.8 & 23.8 & 27.3 & 0.76 & 43.0 & 604.1 & 1191.6 & 16.5 & 23.2 & 0.51 & 24.3 \\
\hline \multirow{2}{*}{ SF } & $S$ & 686.2 & 957.1 & 98.8 & 130.5 & 0.71 & 92.8 & 59.6 & 101.2 & 12.3 & 26.9 & 0.59 & 21.7 & 327.2 & 689.6 & 34.5 & 69.5 & 0.47 & 70.0 \\
\hline & C & 129.1 & 149.7 & 15.6 & 18.1 & 0.86 & 32.3 & 74.8 & 84.8 & 10.5 & 11.2 & 0.88 & 20.4 & 75.2 & 149.6 & 11.2 & 15.9 & 0.50 & 16.4 \\
\hline \multirow{2}{*}{ TW } & S & 46.1 & 156.6 & 93.4 & 310.0 & 0.29 & 87.8 & 11.2 & 30.6 & 22.9 & 31.1 & 0.37 & 34.9 & 11.4 & 32.5 & 27.9 & 79.1 & 0.35 & 573 \\
\hline & C & 2.7 & 8.5 & 7.8 & 13.9 & 0.31 & 1.9 & 22.5 & 46.5 & 21.8 & 25.8 & 0.48 & 44.8 & 3.0 & 7.5 & 8.4 & 5.6 & 0.40 & 4.6 \\
\hline \multirow{2}{*}{ BM } & $S$ & 1396383.9 & 4503702.0 & 13.3 & 27.3 & 0.31 & 17.4 & 917674.8 & 2612189.2 & 11.3 & 15.7 & 0.35 & 24.1 & 3384689.3 & 6483516.8 & 21.1 & 37.6 & 0.52 & 40.4 \\
\hline & C & 1976698.6 & 2380141.0 & 21.7 & 23.8 & 0.83 & 20.9 & 2805522.0 & 4097718.0 & 14.8 & 17.8 & 0.68 & 25.2 & 2045458.3 & 3819606.0 & 11.8 & 16.2 & 0.53 & 17.8 \\
\hline \multirow{2}{*}{$\mathrm{HI}$} & $S$ & 0.003 & 0.005 & 131.1 & 195.6 & 0.63 & 114.9 & 0.013 & 0.018 & 52.7 & 63.4 & 0.71 & 91.2 & 0.004 & 0.009 & 81.4 & 132.3 & 0.45 & 113.6 \\
\hline & C & 0.006 & 0.008 & 16.3 & 21.0 & 0.76 & 29.5 & 0.006 & 0.011 & 13.9 & 19.2 & 0.57 & 21.8 & 0.002 & 0.003 & 11.5 & 9.8 & 0.60 & 18.4 \\
\hline \multirow{2}{*}{ GY } & $S$ & 158336.1 & 259562.3 & 136.1 & 179.7 & 0.61 & 125.9 & 686123.9 & 1205315.8 & 49.8 & 65.9 & 0.57 & 77.3 & 326017.6 & 775389.3 & 81.3 & 125.5 & 0.42 & 108.6 \\
\hline & C & 893608.3 & 1332621.0 & 17.4 & 20.4 & 0.67 & 28.2 & 1504676.8 & 2728539.0 & 20.1 & 27.1 & 0.55 & 30.7 & 1059208.6 & 2101772.5 & 15.1 & 21.3 & 0.50 & 22.1 \\
\hline \multirow{2}{*}{ SPAD } & $S$ & 0.3 & 6.4 & 1.1 & 12.5 & 0.05 & 0.2 & - & - & - & - & - & - & - & - & - & - & - & - \\
\hline & C & 4.6 & 8.4 & 5.4 & 7.3 & 0.55 & 8.3 & - & - & - & - & - & - & - & - & - & - & - & - \\
\hline \multirow{2}{*}{ CT } & $S$ & 0.7 & 3.1 & 2.2 & 4.8 & 0.21 & 2.1 & - & - & - & - & - & - & - & - & - & - & - & - \\
\hline & C & 3.9 & 12.9 & 6.8 & 32.3 & 0.30 & 14.0 & - & - & - & - & - & - & - & - & - & - & - & - \\
\hline
\end{tabular}

DFF: days to $50 \%$ flowering; PH: plant height (cm); PN: panicle number; PL: panicle length (cm); FGP: filled grains per panicle; SF: spikelet fertility; TW: test weight BM: biomass (tha-1); HI: harvest index; GY: grain yield (tha-1); SPAD: chlorophyll content; CT: canopy temperature (0c); DS: dry season; dS: Wet season; S: stress: C: control 
342

Heritability and genetic advance

Heritability estimates were observed to be high for DFF (0.82 to 0.86$), \mathrm{PH}(0.81$ to 0.84$)$, high to moderate for PN (0.57 to 0.77$)$, PL (0.57 to 0.89$)$, FGP (0.51 to 0.83$)$, SF (0.50 to 0.88$), \mathrm{BM}(0.53$ to 0.83$), \mathrm{HI}(0.57$ to 0.76$)$ and GY (0.50 to 0.67$)$, moderate for SPAD $(0.55)$ and low for TW (0.31 to 0.48$)$ and CT $(0.30)$ under control conditions across all seasons. Under stress environment, heritability is high for DFF (0.73 to 0.79 ) and PH (0.69 to 0.83 ), high to moderate for PL (0.30 to 0.57$)$, FGP (0.50 to 0.67$)$, SF (0.47 to 0.71$)$, HI $(0.45$ to 0.71$)$ and GY (0.42 to 0.61$)$, moderate to low for PN (0.28 to 0.55$)$, TW (0.29 to 0.35$)$, BM (0.31 to 0.52 ) and CT (0.21) (DS 2013) and very low for SPAD (0.05) (DS 2013) for all three seasons (Tab. 2). High to moderate heritability was reported for different quantitative traits studied in rice (Berneir et al., 2007; Abarshahr et al., 2011; Akinwale et al., 2011; Sadeghi et al., 2011; Vikram et al., 2011; Saikumar et al., 2014). Similarly DTF and PH were also highly heritable across other studies (Berneir et al., 2007; Vikram et al., 2011; Saikumar et al., 2014).

Further, all traits were influenced by stress environment (drought stress), which is evident from the lower values of heritability estimates in stress with respect to control condition, except for HI and GY in WS 2012. Traits such as $\mathrm{PN}$ and $\mathrm{BM}$ were affected to maximum extent by the environment, in comparison with the rest of the traits. However, TW showed lower values of heritability in both the conditions. Further, the heritability for GY under stress was found similar to that under control in all three years, indicating that selection for GY under reproductive stage stress has practical applicability in improving the GY for drought prone environments. Similar results in the case of heritability for GY under reproductive stage stress were reported in previous studies also (Kumar et al., 2007; Berneir et al., 2007; Abarshahr et al., 2011; Vikram et al., 2011; Saikumar et al., 2014). Selection for GY under RS is now a well-recommended selection criterion for breeding drought-tolerant rice varieties (Kumar et al., 2008). Low heritability indicates a greater role of the environment on the expression of traits (Seyoum et al., 2012).

Similar to the coefficient of variation the value of genetic advance expressed in percent of mean was also high for GY (77.3 to $125.9(\mathrm{~S})$ and 22.1 to $30.7(\mathrm{C})$ ), $\mathrm{HI}$ (91.2 to 114.9 (S) and 18.4 to $29.5(\mathrm{C})), \mathrm{FGP}(33.6$ to $78.5(\mathrm{~S})$ and 24.3 to 44.1(C)), SF (31.7 to $92.8(\mathrm{~S})$ and 20.4 to $32.3(\mathrm{C}))$ and TW (34.9 to $87.8(\mathrm{~S})$ and 21.9 to 44.8$)$ and low for PH (14.1 to $22.9(\mathrm{~S})$ and 8.5 to $15.3(\mathrm{C})), \mathrm{PL}$ (8 to $15.1(\mathrm{~S})$ and 8.6 to $15.1(\mathrm{C}))$, SPAD $(0.2(\mathrm{~S})$ and $8.0(\mathrm{C}))$ and CT $(2.1$ $(\mathrm{S})$ and $14.0(\mathrm{C}))$ under both the conditions, where as moderate estimates of genetic advance were noticed in case of DFF (17.7 to $32.6(S)$ and 14.7 to $18.7(\mathrm{C})$ ), $\mathrm{PN}$ (24.6 to 54.6 and 12.3 to $15.1(\mathrm{C})$ ) and BM (17.4 to $40.4(\mathrm{~S})$ and 17.8 to $25.2(\mathrm{C}))$. High values of genetic advance were recorded for all the studied traits for stress trails rather than control, and dry season trails over wet season, except for PN, $\mathrm{PL}$ and BM.

Further traits such as FGP, GY and HI recorded high heritability as well as GA under both control and stress conditions, consistently across the seasons. Similar results were reported previously (Manickavelu et al., 2006; Yadav et al., 2011). Although other traits showed high heritability values, expected GA was low or moderate to inconsistent.

However, a suitable selection procedure could be followed only when the high broad-sense heritability estimate was coupled with high genetic advance. Since high heritability does not always indicate high genetic gain, heritability with genetic advance should be used in predicting selection of superior genotypes (Ali et al., 2002). The three traits above mentioned, having high values of heritability and genetic advance in percent of mean have emerged as ideal traits for improvement through selection. Further these traits showed high GCV and PCV values, suggesting that they may provide a high response to selection, owing to their high transmissibility and variability.

\section{Correlation}

Magnitude of correlation coefficient at phenotypic level was higher than inherent associations at genotypic level, between different traits in the population. GY was significantly and positively correlated at both phenotypic (p) and genotypic (g) level with FGP (0.35 to 0.71 (p) 0.67 to $0.85(\mathrm{~g})), \mathrm{SF}(0.30$ to $0.75(\mathrm{p}) 0.67$ to $0.83(\mathrm{~g}))$, TW (0.30 to 0.64 (p) 0.59 to $0.75(\mathrm{~g}))$ and HI $(0.94$ to $0.97(\mathrm{p})$ 0.98 to $0.99(\mathrm{~g}))$, negatively and significantly correlated with DFF $(-0.33$ to $-0.56(\mathrm{p})$ and -0.34 to $-0.77(\mathrm{~g}))$ under stress conditions consistently. Whereas under control, traits such as FGP (0.17 to 0.24 (p) 0.29 to $0.39(\mathrm{~g}))$, SF (0.18 to 0.29 (p) 0.40 to $0.41(\mathrm{~g})), \mathrm{BM}(0.54$ to $0.76(\mathrm{p})$ and 0.39 to 0.73 $(\mathrm{g}))$ and HI (0.64 to $0.77(\mathrm{p})$ and 0.70 to $0.78(\mathrm{~g}))$ were positively and significantly correlated with GY, and DFF (0.18 to -0.21 (p) and -0.26 to $-0.28(\mathrm{~g})$ ) was negatively correlated with GY consistently across all three seasons (at $\mathrm{p}<0.05$ and $\mathrm{p}<0.01$ ) (Tab. 3). PH and PN found to positively correlated with GY under stress condition only. BM showed a weak negative correlation with HI under stress during dry season experiments, and was positively correlated with HI under WS 2012 stress and all control conditions. In addition, DFF was also negatively correlated with $\mathrm{HI}$ under both conditions. The positive correlation between GY and PH, FGP, SF, TW, BM and HI has been also emphasized previously by many researchers (Lanceras et al., 2004; Berneir et al., 2007; Vikram et al., 2011). Similarly, the negative correlation between GY and DTF has also been reported (Garrity and O'Toole, 1994; Lanceras et al., 2004; Abarshahr et al., 2011; Varma et al., 2012). In contrast, the negative correlation between $\mathrm{PH}$ and GY was revealed by Laffite et al. (2006).

However, under both conditions HI, FGP and SF were found to be highly correlated with GY consistently, when compared to other quantitative traits, under both the conditions at $\mathrm{p}<0.01$. Whereas, for FGP, SF and HI values of correlation coefficients were found to be high with GY under stress, rather than under control conditions, at both levels. Further, DFF was found to be highly negatively correlated with GY under both the conditions among all the studied traits. As the level of stress increased, correlation between GY and HI increased significantly. Similarly, the negative correlation between GY and DTF emphasized with the increase in stress level. Canopy temperature (DS 2013) was negatively and significantly correlated with GY and other yield related traits. Such a negative correlation between GY and CT is reported in earlier studies also (Hongyan et al., 2005). 
HI, BM, PH were the determining factors for GY under both the conditions, with $\mathrm{HI}$ being the major determinant, indicating that genetic improvement in GY can be accompanied by an improvement in HI (Fukai et al., 1999; Babu et al., 2003)

\section{Path analysis}

Path coefficient analysis permits the separation of the correlation coefficient into components of direct and indirect effect on GY. Path analysis carried out with the help of genotypic correlation coefficients under stress revealed $\mathrm{HI}$ had high positive direct effect on GY ranging from 0.90 to $1.40(\mathrm{HI})$ and followed by $\mathrm{BM}(0.12$ to 0.30$)$,
SF (0.21 to 0.29) and FGP (0.16 to 0.23) (Tab. 4). On the other hand, PN (-0.02 to -0.12) was found to have direct negative effect on GY under stress conditions, during all three seasons. The direct effects of five other traits and two physiological traits were too low or inconsistent to be considered for any consequence. However, most of the traits exhibited indirect influence on grain yield under stress through $\mathrm{HI}$, traits such as $\mathrm{PH}$ (0.12 to 0.51$), \mathrm{PN}$ ( 0.11 to $0.46)$, FGP (0.41 to 0.64$), S F(0.52$ to 0.71$)$ and TW $(0.52$ to 0.86$)$ had an indirect positive effect and DFF (-0.32 to $0.97)$ and BM (-0.07 to -0.37$)$ had an indirect negative effect on GY under stress.

Similarly, under control conditions in addition to HI

Tab. 3a. Phenotypic and genotypic correlation coefficients between yield and yield components traits of the Swarna/WAB450-I-B-P-157-2-1 population under reproductive stage stress (S) (above the diagonal) and control (C) (below the diagonal) conditions in DS 2013

\begin{tabular}{|c|c|c|c|c|c|c|c|c|c|c|c|c|c|c|}
\hline & & & & & & & & $2013 \mathrm{~S}$ & & & & & & \\
\hline & & & DFF & $\mathrm{PH}$ & PN & PL & FGP & SF & $\mathrm{TW}$ & $\mathrm{BM}$ & $\mathrm{HI}$ & $\mathrm{CC}$ & CT & GY \\
\hline & & DFF & 1.00 & -0.07 & 0.07 & -0.11 & $-0.36^{* *}$ & $-0.40^{* *}$ & $-0.37^{* *}$ & 0.01 & $-0.35^{* *}$ & 0.08 & 0.15 & $-0.33^{* *}$ \\
\hline & & PH & 0.04 & 1.00 & -0.10 & $0.68^{* *}$ & $0.40^{* * *}$ & $0.32^{* *}$ & $0.34^{* *}$ & 0.04 & $0.30^{* *}$ & $0.15^{*}$ & -0.15 & $0.31^{* *}$ \\
\hline & & PN & $0.32^{* *}$ & -0.16 & 1.00 & 0.01 & $-0.29^{*}$ & $-0.26^{*}$ & $-0.28^{*}$ & $0.24^{*}$ & $-0.23^{*}$ & 0.08 & 0.04 & $0.16^{*}$ \\
\hline & . & PL & 0.09 & $0.53^{* *}$ & 0.02 & 1.00 & $0.30^{* *}$ & $0.22^{*}$ & $0.24^{*}$ & 0.05 & 0.14 & $0.16^{*}$ & -0.13 & 0.11 \\
\hline & ]ूँ & FGP & $-0.36^{* *}$ & 0.12 & -0.15 & 0.11 & 1.00 & $0.85^{* *}$ & $0.71^{* *}$ & -0.13 & $0.71^{* *}$ & -0.13 & $-0.40^{* *}$ & $0.71^{* *}$ \\
\hline &.$\breve{\breve{n}}$ & SF & $-0.34^{* *}$ & 0.03 & -0.18 & -0.09 & $0.58^{* *}$ & 1.00 & $0.85^{* *}$ & -0.15 & $0.74^{* *}$ & -0.08 & -0.09 & $0.75^{* *}$ \\
\hline & E & TW & $-0.32^{*}$ & $0.27^{* *}$ & -0.16 & $0.22^{*}$ & 0.13 & 0.08 & 1.00 & -0.18 & $0.66^{* *}$ & -0.08 & -0.10 & $0.64^{* *}$ \\
\hline & & BM & 0.06 & 0.11 & $0.29^{*}$ & 0.06 & 0.13 & 0.10 & 0.02 & 1.00 & $-0.25^{*}$ & -0.02 & -0.09 & -0.10 \\
\hline & & HI & $-0.48^{* *}$ & -0.14 & $-0.21^{*}$ & -0.10 & $0.20^{*}$ & $0.28^{*}$ & $0.16^{*}$ & -0.14 & 1.00 & -0.09 & -0.12 & $0.96^{* *}$ \\
\hline & & CC & $-0.21^{*}$ & -0.12 & -0.15 & -0.10 & -0.16 & -0.13 & 0.07 & -0.04 & -0.02 & 1.00 & -0.07 & -0.07 \\
\hline & & CT & 0.11 & $0.18^{*}$ & 0.05 & 0.07 & -0.17 & -0.08 & 0.01 & 0.05 & -0.16 & -0.04 & 1.00 & -0.12 \\
\hline$\stackrel{m}{=}$ & & GY & $-0.21^{*}$ & -0.03 & 0.02 & -0.04 & $0.24^{*}$ & $0.29^{*}$ & 0.14 & $0.54^{* *}$ & $0.75^{* *}$ & -0.04 & -0.10 & 1.00 \\
\hline$\tilde{n}$ & & & DFF & $\mathrm{PH}$ & PN & PL & FGP & SF & $\mathrm{TW}$ & BM & HI & CC & CT & GY \\
\hline & & DFF & 1.00 & -0.07 & 0.15 & -0.15 & $-0.44^{* *}$ & $-0.44^{* *}$ & $-0.39^{* *}$ & 0.03 & $-0.37^{* *}$ & 0.15 & $0.38^{* *}$ & $-0.34^{* *}$ \\
\hline & & $\mathrm{PH}$ & 0.05 & 1.00 & $-0.21^{*}$ & $0.92^{* *}$ & $0.47^{* *}$ & $0.35^{* *}$ & $0.37^{* *}$ & 0.04 & $0.37^{* *}$ & $0.31^{* *}$ & $-0.33^{*}$ & $0.36^{* *}$ \\
\hline & & PN & $0.41^{* *}$ & -0.17 & 1.00 & $-0.25^{*}$ & $-0.67^{* *}$ & $-0.56^{* *}$ & $-0.50^{* *}$ & $0.49^{* *}$ & $-0.48^{* *}$ & $0.27^{*}$ & $-0.43^{* *}$ & $0.19^{*}$ \\
\hline & & PL & 0.10 & $0.58^{* *}$ & 0.05 & 1.00 & $0.36^{* *}$ & $0.30^{* *}$ & $0.32^{* *}$ & 0.05 & $0.22^{*}$ & $0.35^{* *}$ & $-0.34^{* *}$ & 0.14 \\
\hline & 尊 & FGP & $-0.37^{* *}$ & 0.13 & -0.19 & 0.12 & 1.00 & $0.95^{* *}$ & $0.89^{* *}$ & $-0.32^{*}$ & $0.89^{* *}$ & -0.14 & $-0.33^{*}$ & $0.83^{* *}$ \\
\hline & है & SF & $-0.35^{* *}$ & 0.02 & $-0.22^{*}$ & -0.10 & $0.58^{* *}$ & 1.00 & $0.92^{* *}$ & $-0.33^{*}$ & $0.81^{* *}$ & -0.16 & $-0.29^{*}$ & $0.83^{* *}$ \\
\hline & 总 & TW & $-0.53^{* *}$ & $0.52^{* *}$ & $-0.30^{*}$ & $0.37^{* *}$ & $0.22^{*}$ & 0.14 & 1.00 & $-0.37^{* *}$ & $0.74^{* *}$ & -0.18 & $0.24^{*}$ & $0.75^{* *}$ \\
\hline & 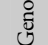 & BM & 0.09 & 0.14 & $0.41^{* *}$ & 0.10 & 0.16 & 0.13 & 0.09 & 1.00 & $-0.29^{*}$ & -0.05 & $0.30^{* *}$ & $-0.22^{*}$ \\
\hline & & HI & $-0.54^{* *}$ & -0.14 & $-0.31^{*}$ & -0.13 & $0.23^{*}$ & $0.31^{* *}$ & $0.34^{* *}$ & $-0.28^{*}$ & 1.00 & -0.14 & $-0.23^{*}$ & $0.98^{* *}$ \\
\hline & & CC & $-0.21^{*}$ & -0.13 & -0.18 & -0.10 & -0.16 & -0.13 & 0.13 & -0.05 & -0.03 & 1.00 & 0.09 & -0.06 \\
\hline & & CT & 0.14 & $0.28^{*}$ & 0.10 & 0.09 & $-0.23^{*}$ & -0.10 & $0.22^{*}$ & 0.12 & $-0.24^{*}$ & -0.06 & 1.00 & $-0.29^{*}$ \\
\hline & & GY & $-0.28^{*}$ & -0.03 & -0.03 & -0.05 & $0.36^{* *}$ & $0.41^{* *}$ & $0.39^{* *}$ & $0.39^{* *}$ & $0.78^{* *}$ & -0.04 & -0.11 & 1.00 \\
\hline
\end{tabular}

(0.72 to 0.96$)$, BM (0.66 to 0.68$)$ was also found to have high positive direct effect on GY, followed by SF (0.11 to $0.17)$ and FGP (0.09 to 0.12). Similar to stress, even under control, the indirect effect exerted by most of the traits is mainly via $\mathrm{HI}$, where FGP $(0.29$ to 0.39$)$, SF (0.40 to 0.41 ) and BM (0.39 to 0.73$)$ had the positive indirect effect, and DFF (-0.26 to - .0 .28$)$ had the negative indirect effect on GY through HI. Yadav et al. (2008), Pandey et al. (2012) found high direct contribution of $\mathrm{HI}$ on GY in rice. Indirect influence of various yield related traits via $\mathrm{HI}$ on GY has been proposed by Singh and Chaudary, (2006), Kotal et al. (2010) and Pandey et al. (2012).

In past, many researchers have emphasized the importance of several quantitative yield component traits as selection criteria for deriving high yielding genotypes in different ecosystems in rice: for example, biomass and harvest index (Lanceras et al., 2004), days to 50\% flowering, flag leaf width and harvest index (Abarshahr et al., 2011), 
344

harvest index (Kumar et al., 2009) under lowland stress, harvest index, plant height and panicle length (Mehetre et al., 1994), filled grains per panicle, spikelet fertility (Seyoum et al., 2012) in upland condition. Spikelet fertility, biomass and harvest index (Pandey et al., 2012), number of spikelets per panicle (Zheng et al., 2003), harvest index, test weight (Kishor et al., 2008), harvest index (Ganesen et al., 1998), number of spikelets per panicle, flag leaf length, plant height (Abarshahr et al., 2011) under irrigated condition. Thus, practical applicability of yield and yield attributing traits, such as days to $50 \%$ flowering, plant height, panicle number, harvest index, spikelet fertility, test weight, biomass and harvest index in rice breeding programme either individually or in combination, as selection criterion represent an effective and feasible approach for pursuing higher yield in the case of rice, which may be due their high direct or indirect effect on GY.

GY under well-watered condition was important in determining GY under water-limiting conditions. Better performance of cultivars with high potential yield under rainfed lowland regions was proposed (Fukai et al., 1999).

Tab. 3b. Phenotypic and genotypic correlation coefficients between yield and yield components traits of the Swarna/WAB450-I-B-P-157-2-1 population under reproductive stage stress (S) (above the diagonal) and control (C) (below the diagonal) conditions in WS 2012

\begin{tabular}{|c|c|c|c|c|c|c|c|c|c|c|c|c|}
\hline & \multicolumn{12}{|c|}{ WS 2012 S } \\
\hline \multirow{22}{*}{ 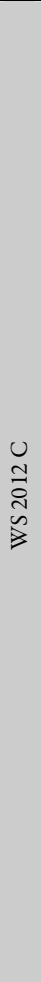 } & \multirow{11}{*}{ 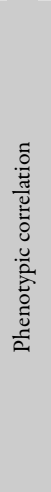 } & & DFF & $\mathrm{PH}$ & $\mathrm{PN}$ & PL & FGP & SF & TW & $\mathrm{BM}$ & $\mathrm{HI}$ & GY \\
\hline & & DFF & 1.00 & 0.15 & -0.09 & $-0.34^{* *}$ & $-0.41^{* *}$ & $-0.26^{*}$ & $-0.45^{* *}$ & $0.23^{*}$ & $-0.65^{* *}$ & $-0.56^{* *}$ \\
\hline & & $\mathrm{PH}$ & $-0.21^{*}$ & 1.00 & $-0.29^{*}$ & 0.12 & 0.04 & 0.02 & -0.03 & 0.12 & -0.16 & $0.15^{*}$ \\
\hline & & $\mathrm{PN}$ & -0.01 & -0.13 & 1.00 & 0.10 & 0.02 & 0.05 & 0.09 & $0.27^{* *}$ & -0.01 & $0.15^{*}$ \\
\hline & & PL & $-0.22^{*}$ & $0.41^{* *}$ & -0.14 & 1.00 & $0.17^{*}$ & 0.09 & $0.32^{* *}$ & -0.02 & $0.24^{*}$ & $0.24^{*}$ \\
\hline & & FGP & $-0.23^{*}$ & $0.23^{*}$ & -0.08 & $0.17^{*}$ & 1.00 & $0.63^{* *}$ & $0.16^{*}$ & -0.03 & $0.36^{* *}$ & $0.35^{* *}$ \\
\hline & & SF & $-0.43^{* *}$ & $0.18^{*}$ & $0.40^{* *}$ & 0.10 & $0.56^{* *}$ & 1.00 & 0.15 & -0.01 & $0.31^{* *}$ & $0.30^{* *}$ \\
\hline & & $\mathrm{TW}$ & -0.01 & 0.14 & -0.13 & 0.13 & $0.19^{*}$ & 0.01 & 1.00 & -0.03 & $0.31^{* *}$ & $0.30^{* *}$ \\
\hline & & $\mathrm{BM}$ & $0.16^{* *}$ & 0.08 & 0.11 & -0.03 & 0.10 & 0.00 & 0.12 & 1.00 & -0.12 & $0.16^{*}$ \\
\hline & & HI & -0.57 & 0.03 & -0.04 & 0.04 & $0.17^{*}$ & $0.34^{* *}$ & -0.04 & $0.19^{*}$ & 1.00 & $0.94^{* *}$ \\
\hline & & GY & $-0.21^{*}$ & 0.07 & 0.05 & 0.01 & $0.18^{*}$ & $0.22^{*}$ & 0.11 & $0.76^{* *}$ & $0.77^{* *}$ & 1.00 \\
\hline & \multirow{11}{*}{ 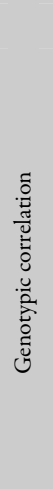 } & & DFF & $\mathrm{PH}$ & $\mathrm{PN}$ & PL & FGP & SF & TW & $\mathrm{BM}$ & $\mathrm{HI}$ & GY \\
\hline & & DFF & 1.00 & $0.20^{*}$ & -0.13 & $-0.62^{* *}$ & -0.64 & $-0.59^{* *}$ & $-0.61^{* *}$ & $0.76^{* *}$ & $-0.80^{* *}$ & $-0.77^{* *}$ \\
\hline & & PH & $-0.24^{*}$ & 1.00 & $-0.66^{* *}$ & $0.17^{*}$ & -0.06 & -0.15 & -0.04 & $0.45^{* *}$ & -0.13 & $0.18^{*}$ \\
\hline & & $\mathrm{PN}$ & -0.01 & -0.17 & 1.00 & -0.17 & -0.33 & $-0.25^{*}$ & $0.16^{*}$ & $0.19^{*}$ & 0.10 & $0.16^{*}$ \\
\hline & & PL & $-0.24^{*}$ & $0.55^{* *}$ & -0.14 & 1.00 & 0.36 & $0.17^{*}$ & $0.72^{*}$ & $-0.48^{* *}$ & $0.63^{* *}$ & $0.70^{* *}$ \\
\hline & & FGP & $-0.25^{*}$ & $0.33^{* *}$ & -0.09 & $0.19^{*}$ & 1.00 & $0.86^{* *}$ & $0.24^{*}$ & $-0.27^{*}$ & $0.80^{* *}$ & $0.67^{* *}$ \\
\hline & & SF & $-0.49^{* *}$ & $0.26^{*}$ & 0.05 & 0.11 & $0.62^{* *}$ & 1.00 & 0.11 & $0.21^{*}$ & $0.97^{* *}$ & $0.82^{* *}$ \\
\hline & & $\mathrm{TW}$ & -0.01 & $0.20^{*}$ & -0.14 & 0.13 & $0.21^{*}$ & 0.01 & 1.00 & -0.09 & $0.54^{* *}$ & $0.59^{* *}$ \\
\hline & & $\mathrm{BM}$ & $0.24^{*}$ & 0.15 & 0.14 & -0.03 & 0.11 & 0.01 & 0.15 & 1.00 & $-0.67^{* *}$ & $-0.27^{*}$ \\
\hline & & $\mathrm{HI}$ & $-0.74^{* *}$ & 0.10 & -0.05 & 0.05 & $0.17^{*}$ & $0.47^{* *}$ & -0.04 & 0.04 & 1.00 & $0.99^{* *}$ \\
\hline & & GY & $-0.26^{*}$ & $0.16^{*}$ & 0.07 & 0.02 & $0.29^{*}$ & $0.40^{* *}$ & $0.16^{*}$ & $0.73^{* *}$ & $0.70^{* *}$ & 1.00 \\
\hline
\end{tabular}

Although yield potential has no direct genetic relationship to drought tolerance, under drought stress it contributed to higher grain yield. On the other hand, GY under very severe stress was mainly related to BY and HI. In a study conducted on pearl millet under drought stress condition (Yadav et al., 2002) HI and the GY would likely be accompanied by an improvement of BM. The indirect effect of FGP and SF under stress through $\mathrm{HI}$ indicated that direct selection using FGP and SF along with $\mathrm{HI}$ to select high yielding genotypes will be effective under stress condition, whereas under control condition selection based on traits such as FGP, SF, BM and HI will be quite useful in breeding programs. The strong genetic correlation between GY and HI resulted in a high direct effect on grain yield.

The value of residual effect ranged from 0.17 to 0.21 under stress and 0.21 to 0.25 under control, indicating that the effect of component traits leading to genetic variability on GY is ranged from $83 \%$ to $79 \%$ in stress and $79 \%$ to $75 \%$ under control conditions by the ten common traits across all three seasons and two physiological traits (DS 2013) that were studied under both the conditions (Tab. 4).

\section{Conclusion}

Results from the above study suggest that there is an adequate genetic variability present in the material studied under stress and irrigated condition. Further characters viz. harvest index, filled grains per panicle, spikelet fertility, panicles per plant, plant height, biomass and days to $50 \%$ flowering influenced the yield either directly or indirectly. Genotypes that are capable of maintaining high harvest index, biomass, spikelet fertility, more filled grains per panicle, panicles per plant and reduced plant height and 
Tab. 3c. Phenotypic and genotypic correlation coefficients between yield and yield components traits of the Swarna/WAB450-I-B-P-157-2-1 population under reproductive stage stress (S) (above the diagonal) and control (C) (below the diagonal) conditions in DS 2012

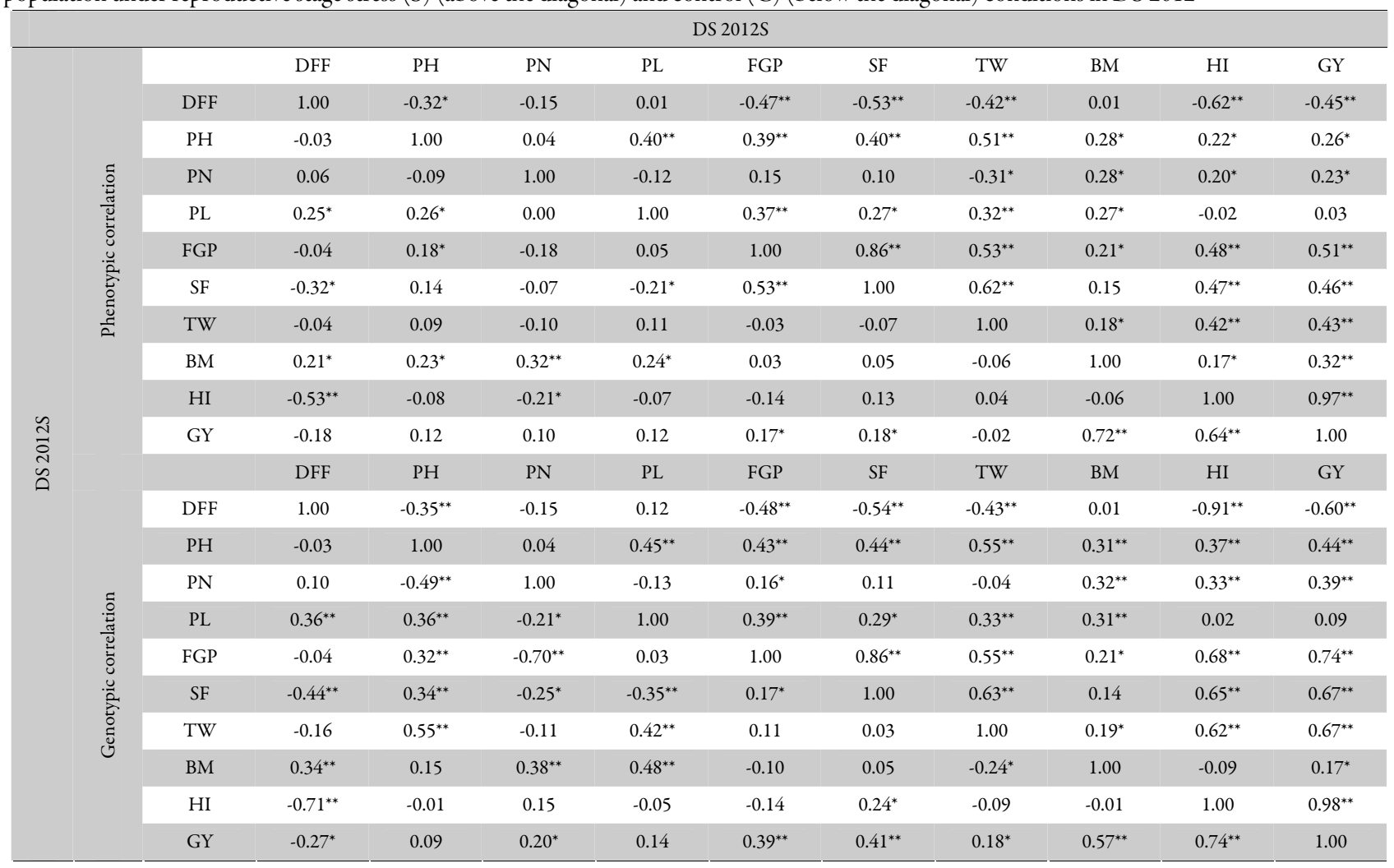

Tab. 4a. Direct (diagonal values) and indirect effects of different characters on grain yield at genotypic level under stress DS 2013, WS 2012 and DS 2012

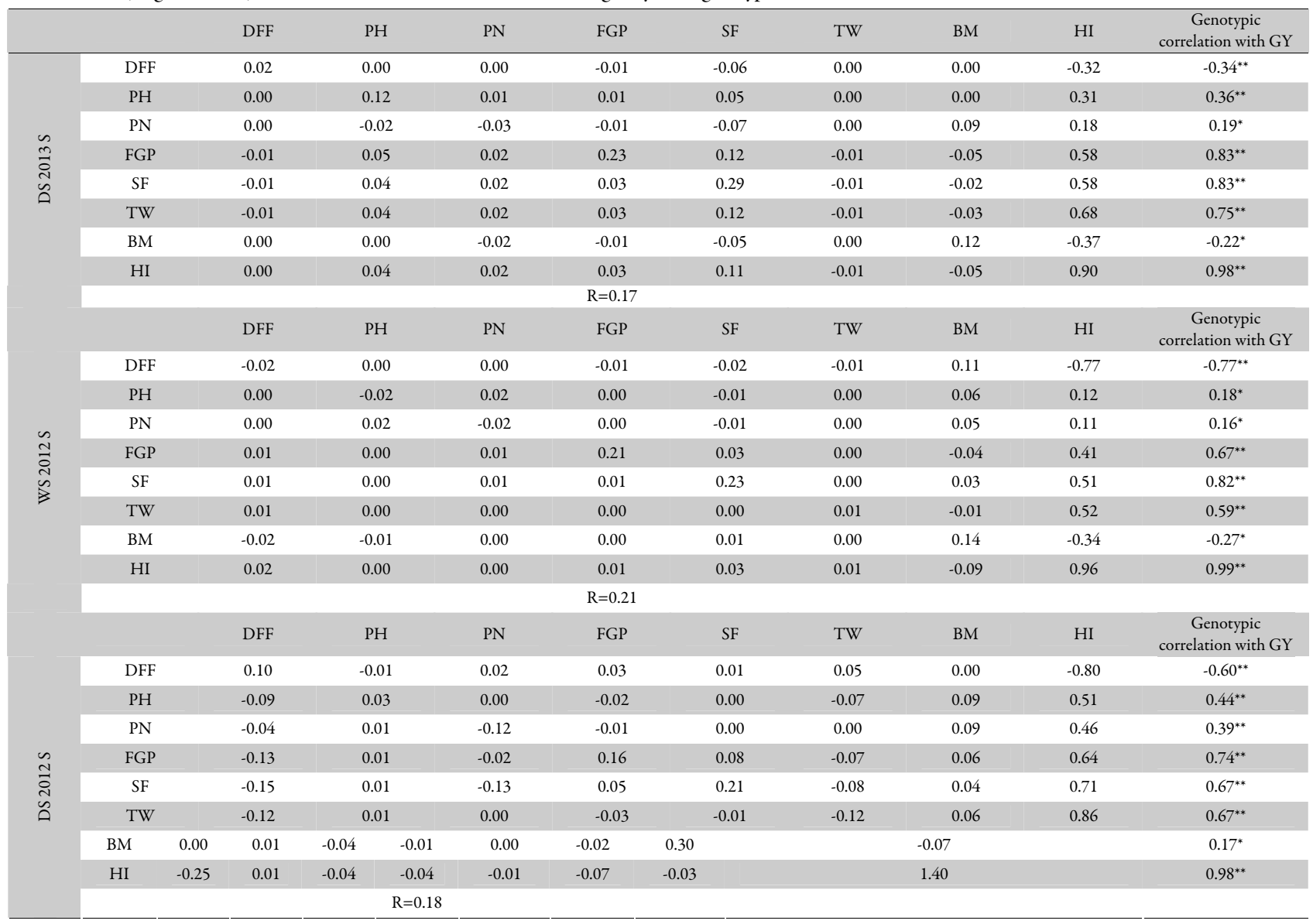


346

Tab. 4b. Direct (diagonal values) and indirect effects of different characters on grain yield at genotypic level under control DS 2013, WS 2012 and DS 2012

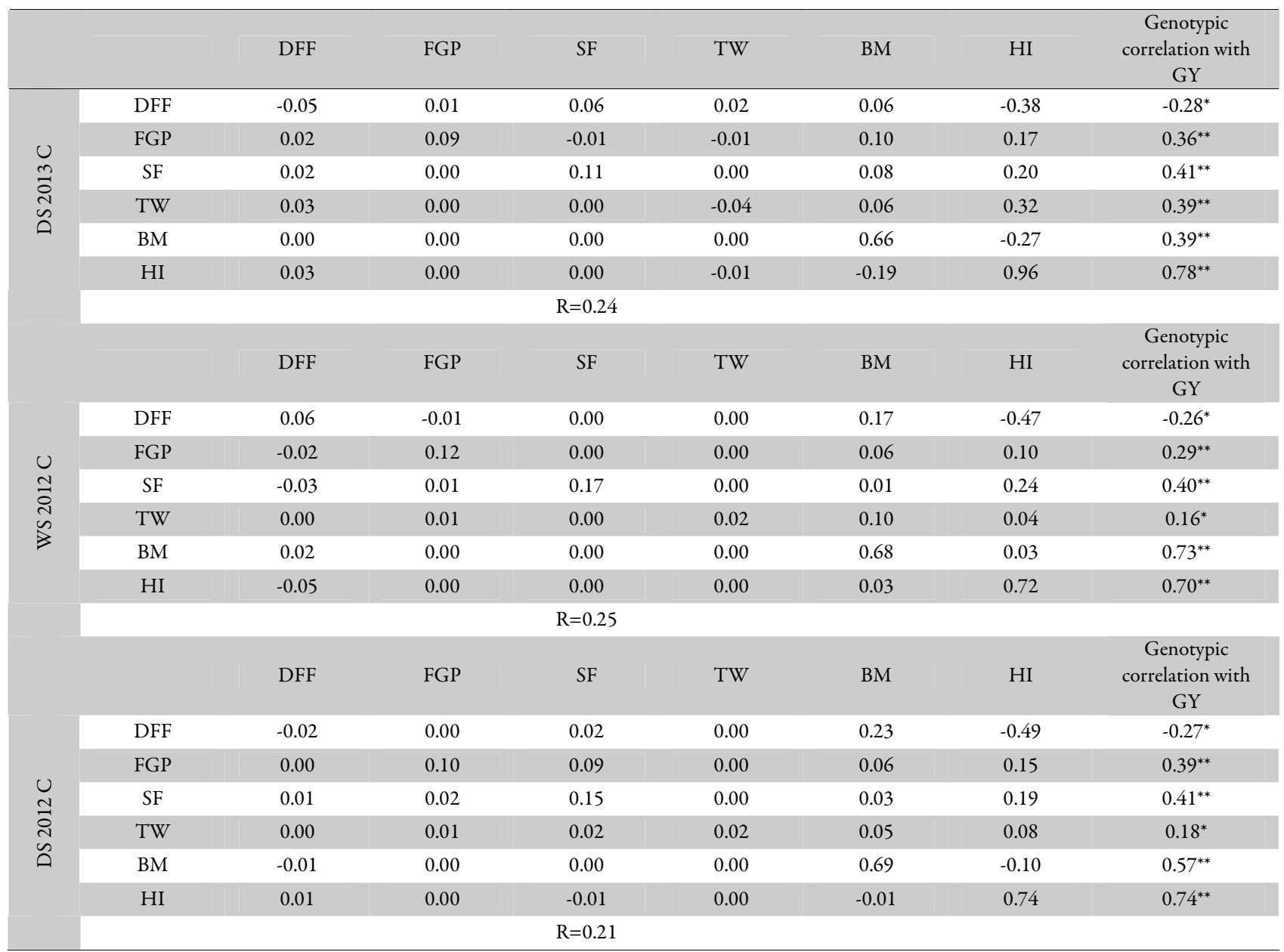

days to $50 \%$ flowering can be considered as suitable for improving the grain yield in rice breeding programs targeting lowland drought.

\section{Acknowledgement}

We thank Management of Barwale Foundation for all the encouragement and support provided during the project.

\section{References}

Abarshahr M, Rabiei B, Slahigi H (2011). Genetic Variability, Correlation and Path Analysis in Rice under Optimum and Stress Irrigation Regimes. Not Sci Biol 3(4):134-142.

Akiniwale AG, Gregorio G, Nwilene F, Akinyele BO, Ogunbayo SA, Odiyo AC (2011). Heritability and correlation coefficient analysis for yield and its components in rice (Oryza sativa L.) Afr J Plant Sci 5:207-212.

Ali A, Khan S and Asad MA (2002). Drought tolerance in wheat: Genetic variation and heritability for growth and ion relations. Asian J Plant Sci 1:420-422.

Atlin GN, Lafitte HR, Tao D, Amante M, Courtois B (2006).
Developing rice cultivar for high fertility upland system in the Asian tropics. Field Crops Res 97:43-52.

Babu RC, Nguyen BD, Chamarerk V, P. Shanmugasundaram, P. Chezhian, Jeyaprakash P, Ganesh SK, Palchamy A, Sadasivam S, Sarkarung, S, Wade LJ, Nguyen HT (2003). Genetic analysis of drought resistance in rice by molecular markers: association between secondary traits and field performance. Crop Sci 43:1457-1469.

Bernier J, Kumar A, Venuprasad R, Spaner D, Atlin GN (2007). A large-effect QTL for grain yield under reproductive-stage drought stress in upland rice. Crop Sci 47:507-516.

Bouman BAM, Peng S, Castañeda AR, Visperas RM (2005). Yield and water use of irrigated tropical aerobic rice systems. Agric Water Manage 74:87-105.

Bouman BAM, Humphreys E, Tuong TP, Barker R (2007). Rice and water. Adv Agron 92:187-237.

Chakroborthy S, Das PK, Guha B, Barman KKS (2010). Quantitative Genetic Analysis for Yield and Yield Components in Boro Rice (Oryza sativa L.) Not Sci Biol 2(1):117-120.

Cruz RT, O’Toole JC, Dingkuhn Yambao EB, Thangaraj M, De Dutta SK (1986). Shoot and root responses to water deficits in rainfed lowland rice. Australian J Plant Physiol 13:567-575. 
Dewey DR, KH Lu (1959). A correlation and path coefficient analysis of components of crested wheat grass seed production. Agronomy Journal 51:515-518.

Farooq M, Wahid A, Lee D J, Ito O, Siddique KHM (2009). Advances in drought resistance of rice. Critical Reviews in Plant Science 28:199-217.

Fukai S, Cooper M (1995) Development of drought-resistant cultivars using physio-morphological traits in rice. Field Crops Res 40:67-87.

Fukai, S, Pantuwan G, Jongdee B, Cooper M (1999). Screening for drought resistance in rainfed lowland rice. Field Crops Res 64:61-74.

Ganesan K, Subramaniam M, Wilfred MW, Sundaram T (1998). Correlation and path coefficient analysis of yield components in $\mathrm{F} 2$ and $\mathrm{F} 3$ generations of tall $\mathrm{x}$ dwarf rice cross. Oryza 35(4):329-332.

Garrity DP, O’Toole JC (1994). Screening rice for drought resistance at the reproductive phase. Field Crop Res 39(2-3):99100.

Hongyan L, Guihua Z, Guolan L, Songpin H, Mingshou L, Xinqiao Y, Hanwei M, Lijun L (2005). Correlation analysis and QTL identification for canopy temperature, leaf water potential and spikelet fertility in rice under contrasting moisture regimes. Chinese Science Bulletin 50(4):317-326.

Ji XM, Raveendran M, Oane R, Ismail A, Lafitte R, Bruskiewich R, Cheng SH, Bennett J (2005). Tissue-specific expression and drought responsiveness of cell-wall invertase genes of rice at flowering. Plant Mol Biol 59:945-964.

Johnson HW, Robinson HF, Comstock RE (1955). Genotypic and phenotypic correlations in soyabean and their implications in selection. Agro J 47:177-483.

Kishor C, Prasad Y, Haider ZA, Kumar R, Kumar K (2008). Quantitative analysis of upland rice. Oryza 45(4):268-274.

Kotal BD, Das A, Chaudary BK (2010). Genetic variability and association of characters in wheat (Triticum aestivum L.). Asian J Crop Sci 2:155-160.

Kumar R, Venuprasad R, Atlin GN (2007). Genetic analysis of rainfed lowland rice drought tolerance under naturallyoccurring stress in eastern India: heritability and QTL effects. Field Crops Res 103:42-52.

Kumar A, Bernier J, Verulkar S, Lafitte HR, Atlin GN (2008). Breeding for drought tolerance: direct selection for yield, response to selection and use of drought tolerant donors in upland and lowland-adapted populations. Field Crops Res 107:221-231.

Kumar A, Verulkar SB, Dixit S, Chauhan B, Bernier J, Venuprasad R, Zhao D, Shrivastava MN (2009). Yield and yield-attributing traits of rice (Oryza sativa L.) under lowland drought and suitability of early vigor as a selection criterion. Field Crops Res 114:99-107.

Lafitte HR, Li ZK, Vijayakumar CHM, Gao YM, Shi Y, Xu JL, Fu BY, Ali AJ, Domingo J, Maghirang R, Torres R, Mackill D (2006). Improvement of rice drought tolerance through backcross breeding: Evaluation of donors and selection in drought nurseries. Field Crops Res 97:77-86.
Lanceras J, Pantuwan G, Jongdee B, Toojinda T (2004). Quantitative trait loci associated with drought tolerance at reproductive stage in rice. Plant Physiol 135:384-399.

Maclean JL, Dawe DC, Hardy B, Hettel GP (2002). Rice Almanac. Los Banos, Philippines: International Rice Research Institute.

Manickavelu A, Gnanamalar R Nadarajan N, Ganesh SK (2006). Genetic variability studies on different population of rice under drought condition. J Plant Sci 1:332-339.

Mehetre SS, Mahajan CR, Patil PA, Land SK, Dhumal PM (1994). Variability, heritability, correlation, path analysis and genetic divergence studies in upland rice. IRRI Note 19(1):8-10.

O'Toole JC (1982). Adaptation of rice to drought prone environments. In Drought Resistance in Crops with Emphasis on Rice. IRRI, Los Banos, Philippines, pp. 195-213.

Pandey VR, Singh PK, Verma OP, Pandey P (2012). Interrelationship and path coefficient estimation in rice under salt stress environment. Int J Agric Res 7(4):169-184.

Panse VG, Sukhatme PV (1985). Statistical Methods for Agricultural Workers, 2nd edition, Indian Council of Agricultural Research Publication, New Delhi.

Pantuwan G, Fukai S, Cooper M, Rajatasereekul S, O’Toole JC (2002). Yield response of rice (Oryza sativa L.) genotypes to drought under rainfed lowlands. Selection of drought resistant genotypes. Field Crops Res 73:169-180.

Peng S, Cassman KG, Virmani SS, Sheehy J, Khush GS (1999). Yield potential trends of tropical rice since the release of IR8 and the challenge of increasing rice yield potential. Crop Sci 39:1552-1559.

Sadeghi T (2011). Heritability, phenotypic correlation and path coefficient studies for some agronomic characters in landrace varieties. World Applied Sci J 13:1229-1233.

Saikumar S, Kalmeshwer GP, Saiharini A, Varma CMK, Vineesha O, Padmavathi G, Shenoy VV (2014). Major QTL for enhancing rice grain yield under lowland reproductive drought stress identified using an $O$. sativa/O. glaberrima introgression line. Field Crops Res 163:119-131.

Saini HS, Westgate ME (2000). Reproductive development in grain crops during drought. Adv Agron 68:59-96.

Selvarani M, Rangasamy P (1997). Variability studies for physiological traits and yield components in rice. Madras Agri J 84:44-45.

Serraj R, Kumar A, McNally KL, Slamet-Loedin I, Bruskiewich R, Mauleon R, Cairns J, Hijmans RJ (2009). Improvement of drought resistance in rice. Adv Agron 103:41-99.

Seyoum M, Alamerew S, Bantte K (2012). Genetic variability, heritability, correlation coefficient and path analysis for yield and yield related traits in rice (Oryza sativa L.). J Plant Sci 1-10.

Singh GP, Chaudary HB (2006). Selection parameters and yield enhancement of wheat (Triticum aestivum L.) under different moisture conditions. Asian J Plant Sci 5:894-898.

Varma CMK, Kalmeshwer GP, Saikumar S, Shenoy V, HE Shashidhar, Sarla N (2012). Transgressive Segregation for Yield Traits in Oryza sativa IR58025B X Oryza meridionalis Ng. Bc2F3 Population under Irrigated and Aerobic Conditions. J Crop Sci Biotech 15(3):231-238. 
348

Venkataramana P, Hittalmani S (1990). Genetic variability of some important traits in two F2 segregants in rice under non submergence condition. Crop Res 18:53-56.

Venuprasad R, Dalid CO, Del Valle M, Zhao D, Espiritu M, Sta Cruz MT, Amante M, Kumar A, Atlin GN (2009). Identification and characterization of large-effect quantitative trait loci for grain yield under lowland drought stress in rice using bulk-segregant analysis. Theor Appl Genet 120:177-190.

Vikram P, Swamy BPM, Dixit S, Sta Cruz T, Ahmed HU, Singh AK, Kumar A (2011). qDTY1.1, a major QTL for rice grain yield under reproductive-stage drought stress with a consistent effect in multiple elite genetic backgrounds. BMC Genet 12:89.

Yadav SC, MK Pandey, and Suresh BG (2008). Association of direct and indirect effect of yield attributing trait on yield in rice (Oryza sativa L.) Ann Bio 24:57-62.

Yadav SK, P Pandey, B Kumar, Suresh BG (2011). Genetic architecture, interrelationship and selection criteria for yield improvement in rice (Oryza sativa L.) PakJ Biol Sci 14:540-545.
Yadav RS, Hash CT, Bidinger FR, Cavan GP, Howarth CJ (2002) Quantitative trait loci associated with traits determining grain and stover yield in pearl millet under terminal drought-stress conditions. Theor Appl Genet 104:67-83.

Yambao EB, Ingram KT (1988). Drought stress index for rice. Philippine Journal of Crop Science 13(2):105-111.

Yoshida S, Hasegawa S (1982). The rice root system, its development and function. In: Drought resistance in crops with the emphasis on rice. Manila IRRI, pp. 83-96.

Zheng JG, Ren GJ, Lu XJ, Jiang XL (2003). Effect of water stress on rice grain yield and quality after heading stage. Chin J Rice Sci 3:239-243.

Zhu QH, Ramm K, Shivakkumar R, Dennis ES, Upadhyaya NM (2004). The anther indehiscencel gene encoding a single MYB domain protein is involved in anther development in rice. Plant Physiol 135:1514-152. 